RELACult - Revista Latino-Americana de Estudos em Cultura e Sociedade

Revista Latinoamericana de Estudios en Cultura y Sociedad | Latin American Journal of Studies in Culture and Society

V. 02, Ed. Especial, dezembro, 2016, p. 495-506 | periodicos.claec.org e-ISSN 2016/Atual: 2525-7870 | e-ISSN 2015/2016: 2447-018X

\title{
NOS INTRAMUROS DO LICEU: violência escolar em Belo
}

Horizonte.

\author{
INTRAMUROS EN EL LICEO: la violencia escolar en Belo Horizonte. \\ INSIDE THE WALLS: school violence in Belo Horizonte.
}

\author{
Me. Paulo Tiego Gomes de Oliveira ${ }^{1}$
}

\begin{abstract}
Resumo
O artigo apresenta dados sobre fenômenos violentos resultantes de questões étnico-raciais no ambiente escolar de Belo Horizonte em 2014 e 2015. Identifica qual grupo étnico-racial figura como vítima mais recorrente de crimes e contravenções em escolas públicas do ensino médio na capital mineira. Observando a dinâmica que se constrói no cenário escolar diante das implicações étnico-raciais resultantes de preconceito e racismo, tem como referencial teórico Charlot, Gomes, Munanga, Soares e Teixeira. Utiliza leis em vigor, dentro dos temas de educação, racismo, preconceito e violência racial. A hipótese é que são os indivíduos de etnia negra (pardos e pretos) os mais vitimizados. Utiliza a metodologia quantitativa, através da coleta de boletins de ocorrência policial buscando discutir e refletir sobre a possível naturalização da violência contra grupos étnico-raciais negros dentro do ambiente escolar.
\end{abstract}

Palavras-chave: Ambiente escolar; Cútis; Preconceito; Sexo Biológico.

\section{Resumen}

El artículo presenta datos sobre fenómenos violentos que resultan de cuestiones étnicas y raciales en el entorno escolar de Belo Horizonte, en 2014 y 2015. En él se identifican los cuales figura étnica y racial grupo ya que la mayoría víctima recurrente de delitos y faltas en las escuelas secundarias públicas en la capital del estado. Tomando nota de la dinámica que se construye en el entorno escolar sobre las implicaciones étnicas y raciales de los prejuicios y el racismo, es teórico Charlot, Gomes, Munanga, Soares y Teixeira. Utilizar las leyes vigentes en el temas de educación, el racismo, los prejuicios y la violencia racial. La hipótesis es que son los individuos de origen negro (negro y mixto) los más victimizados. Se utiliza la metodología cuantitativa mediante la recopilación de los informes policiales que tratan de discutir y reflexionar sobre la posible naturalización de la violencia contra los grupos étnico-raciales negros en el medio escolar.

Palabras-clave: Ambiente escolar; Cutis; El prejuicio; El sexo biológico.

\begin{abstract}
The article presents data on violent phenomena resulting from ethnic and racial issues in the school environment of Belo Horizonte in 2014 and 2015. It identifies which ethnic and racial group figure as most recurrent victim of crimes and misdemeanors in public high schools in the state capital. Noting the dynamic that is built in the school setting on the ethnic and racial implications of prejudice and racism, is theoretical Charlot, Gomes, Munanga, Soares and Teixeira. Use laws in force within the education issues, racism, prejudice and racial violence. The hypothesis is that they are individuals of black ethnicity (black and mixed) the most victimized. It uses quantitative methodology by collecting police reports seeking to discuss and reflect on the possible naturalization of violence against black ethnic-racial groups within the school environment.
\end{abstract}

Keywords: school; Cutis; Loss; Biological sex.

\footnotetext{
${ }^{1}$ Mestre em Ciências Sociais; Universidade Federal de Minas Gerais - UFMG; Belo Horizonte, Minas Gerais, Brasil; ptiego@hotmail.com.
} 


\section{Introdução}

Primeiramente esclarece-se que o título dessa pesquisa faz referência ao sinônimo mais antigo da palavra Liceu, que no sentido desse estudo é o mesmo que escola ou local de ensino, pois era esse o termo que se referia à escola filosófica fundada por Aristóteles em 335 aC. E era uma das três mais importantes escolas de Filosofia da Antiguidade. O Liceu existiu de fato e foi descoberto em 1996 durante obras para a construção do novo Museu de Arte Moderna de Atenas. Localiza-se próximo ao atual Parlamento grego, à Acrópole, e ao Parthenon (EXAME, 2014).

Decorridos quase trinta anos da promulgação da lei $n^{0} 7.716$ de 5 de janeiro de 1989 , que pune atos de preconceito de raça ou de cor, ainda são muitos os registros nos órgãos de Segurança Pública. Todavia, maiores seriam se, de fato, todas as vítimas denunciassem tais atos e se todos os operadores da segurança pública reconhecessem tais atos como crimes e violações de direitos humanos, posto que no cenário atual, ainda, é um grande desafio para a população negra conseguir um acolhimento institucional das denúncias de racismo.

Segundo dados da Polícia Civil de Minas Gerais, depois de registrar queda entre 2011 e 2013, os crimes de racismo voltaram a subir e somaram 326 (trezentas e vinte e seis) denúncias em 2015. Os 147 (cento e quarenta e sete) crimes denunciados em 2013 resultavam em uma média de um delito a cada 60 horas. Com a elevação em 2015, os registros passam para 27 (vinte e sete) crimes por mês, quase um por dia.

Apesar de a sociedade brasileira se dizer "não racista", os exemplos que sabemos são tantos, que foi preciso criar leis, a Lei $\mathrm{n}^{\circ} 7.716 / 1989$, que define os crimes resultantes de preconceito de raça ou de cor e a Lei no 12.288/ 2010, Estatuto da Igualdade Racial, visando à promoção da igualdade racial no Brasil (BRASIL, 2010).

No que diz respeito ao alargamento do conceito de direitos humanos e sua implicação no processo de constituição da educação, enquanto força motriz da sociedade e, mais detidamente, enquanto um aspecto que gera direitos para além do Estado, observamos a dificuldade em se inserir na grade escolar temas que abordam questões sobre diversidade e gênero. O tema da 'Educação e relações étnico-raciais' mostra-se ideal para novas imersões na esfera do ensino e do conhecimento, especialmente, na rede de escolas públicas que acabam por acolher a maioria dos alunos das periferias país afora.

Diante de tais apontamentos iniciais, identificar quais grupos étnico-raciais figuram como vítimas e autores mais recorrentes de eventos de Defesa Social (crimes e contravenções) no espaço escolar, em Belo Horizonte, em 2014 e 2015, é crucial. Para tanto, obter a 

e-ISSN 2016/Atual: 2525-7870 | e-ISSN 2015/2016: 2447-018X

quantificação e qualificação dos registros policiais do banco de dados de ocorrências da PMMG sobre a violência em um recorte de ocorrências no espaço escolar em Belo Horizonte nos permite se aproximar da resposta.

Nossa hipótese é a de que são os estudantes negros as maiores vítimas tendo por base o fato das inúmeras narrativas que a mídia divulga sobre a violência que ocorre em ambientes escolares. Tal hipótese ganha repercussão quando observamos que em 2012, 56.000 (cinquenta e seis mil) pessoas foram assassinadas no Brasil e que trinta mil delas eram jovens entre 15 a 29 anos, onde 77\% eram negros. A categoria negros, de forma político-identitária, contempla a população de pardos e pretos. Mesmo com alarmante constatação, demonstrada na frieza dos números, a questão não tem tido a pauta necessária na agenda política nacional (ANISTIA INTERNACIONAL, 2015).

\section{Referencial teórico}

Existe uma constante discordância em torno dos termos que melhor podem representar grupos, pessoas ou etnias negras. Isso ocorre porque entre "autores, intelectuais e militantes com perspectivas teóricas e ideológicas diferentes não há consenso, e isso se agrava a depender da área do conhecimento e do posicionamento político dos mesmos", Gomes (2012). Para os fins propostos nessa pesquisa, o termo negro é utilizado na perspectiva de Santos (2002), pois

\footnotetext{
Se justifica agregarmos pretos e pardos para formarmos, tecnicamente, o grupo racial negro, visto que a situação destes dois últimos grupos raciais é, de um lado, bem semelhante, e, de outro lado, bem distante ou desigual quando comparada com a situação do grupo racial branco. Assim sendo, ante a semelhança estatística entre pretos e pardos em termos de obtenção de direitos legais e legítimos, pensamos ser plausível agregarmos esses dois grupos raciais numa mesma categoria, a de negros. (...) a diferença entre pretos e pardos no que diz respeito à obtenção de vantagens sociais e outros importantes bens e benefícios (ou mesmo em termos de exclusão dos seus direitos legais e legítimos) é tão insignificante estatisticamente que podemos agregá-los numa única categoria, a de negros, uma vez que o racismo no Brasil não faz distinção significativa entre pretos e pardos, como se imagina no senso comum (p.13).
}

Como visto, nos parece adequado à junção de pretos e pardos, que além de ser salutar é eticamente correto, uma vez que denotam mais similaridades do que discrepâncias, o que reforça a validade do agrupamento. Segundo Munanga (1994), o debate que transpõe algumas barreiras Brasil afora é decorrente de questões que gravitam em torno da identidade dos sujeitos: 
A tomada de consciência de um segmento étnico-racial excluído da participação na sociedade, para a qual contribuiu economicamente, com trabalho gratuito como escravo, e também culturalmente, em todos os tempos na história do Brasil (MUNANGA, p.187).

Desta feita, a discussão sobre raça e racismo no Brasil e seus muitos efeitos cotidianos em nossa sociedade perpassa não só gerações, mas encontra desafios constantes na busca de legitimidade e reconhecimento. Compreender a dinâmica que se constrói no ambiente escolar diante de atos infracionais e criminais que ocorrem na escola, revela que a questão étnicaracial é impactante nesse cenário e demarca indivíduos em razão da violência oriunda do preconceito racial. Para tanto lançamos mão daquilo que explica Charlot (2002), em estudo realizado na França:

(...) Essa violência contra a escola deve ser analisada junto com a violência da escola: uma violência institucional, simbólica, que os próprios jovens suportam através da maneira como a instituição e seus agentes os tratam (modos de composição das classes, de atribuição de notas, de orientação, palavras desdenhosas dos adultos, atos considerados pelos alunos como injustos ou racistas). (p.434-435).

Para o autor há que se fazerem distinções entre os atos violentos que ocorrem na seara do espaço escolar. Desta forma, seria possível discernir que ações seriam mais aptas a criar soluções. Para cada tipo de violência (verbal, física ou simbólica) a ação que se espera é variada, não sendo engessada, visto que é um fenômeno multifacetado da dinâmica que se impõe nesse cenário social.

Parece-nos que "diante dessas representações e estigmas, o jovem tende a ser visto na perspectiva da falta, da incompletude, da irresponsabilidade, da desconfiança, o que torna mais difícil para a escola perceber quem ele é de fato, o que pensa e é capaz de fazer" (DAYRELL, 2007, p.1117). Tratando-se de uma pesquisa que almeja ser realizada em escolas públicas, em uma sociedade tão diversa como é a brasileira, lidar com a diferença tem sido cada vez mais urgente, pois o racismo, sendo uma definição conceitual complexa, tende a ser abordado a partir da perspectiva que consiste em por brancos de um lado e negros de outro. $\mathrm{O}$ entendimento de raça é uma construção social, que se diferencia da realidade biológica, vejamos:

[...] O termo cor substitui o de raça, mas deixou à mostra todos elementos das teorias racistas - cor, no Brasil, é mais que cor de pele: na nossa classificação, a textura do cabelo e o formato de nariz e lábios, além de traços culturais, são elementos importantes na definição de cor (preto, pardo, amarelo e branco). Suprimia-se o termo raça sem que o processo social de marcação de diferenças e fronteiras entre grupos humanos perdesse o seu caráter reducionista e naturalizador. (GUIMARÃES, 2011, p.266). 
O preconceito e a discriminação raciais são apenas duas das muitas formas que se manifestam o racismo, visto que são mais percebidos na forma de pré-julgamentos, estigmatizações diversas e generalizações pautadas em traços físicos, o que desaguaria em preconcepções baseadas em determinados estereótipos.

Sendo fato social que ocorre em qualquer espaço, a escola além de carregar a missão de ensinar indivíduos a viver e conviver com a diversidade que forma nossa sociedade, está entre os principais locais institucionais onde esse problema se reproduz.

\begin{abstract}
Lamentavelmente, nem sempre damos a essas dimensões simbólicas a devida atenção dentro do ambiente escolar e, quando o fazemos, nem sempre as consideramos dignas de investigação científica e merecedoras de um trato pedagógico. Dessa forma, um dos caminhos para a ampliação do estudo da questão racial no campo da educação, na tentativa de compreender a sua relação com o universo simbólico, pode ser a construção de um olhar mais alargado sobre a educação como processo de humanização, que inclua e incorpore os processos educativos não escolares (GOMES, 2002, p.40).
\end{abstract}

Conforme a autora reside na escola a falta discussões que, aparentemente, soam como menores diante dos olhos dos educadores, não sendo alvo de maior esforço acadêmico ou mesmo pedagógico. Todavia, são essas pequenas ações que poderiam estar fazendo a diferença na leitura de mundo dos sujeitos, que uma vez implicados em dinâmicas e ações comportamentais, poderiam criar uma sociedade mais adaptada à diferença, a aceitação, respeito e a diversidade. Que resultaria em superar a ideologia de subordinação/submissão baseadas em cor, gênero, sexo, religião e outros estigmas.

Práticas cidadãs extrapolam os muros da escola e devem partir de um movimento de mão dupla, permitindo com que novas práticas educacionais sejam postas em ação, mesmo porque o processo de aprendizagem é maior que a relação professor e aluno. Gomes (2005) reforça essa prática na educação: "ainda encontramos muitos (as) educadores (as) que pensam que discutir sobre relações raciais não é tarefa da educação".

\title{
2.1 Apontamentos iniciais
}

Vemos crescer práticas e comportamentos que excluem indivíduos na sociedade, seja pela discriminação que há contra negros, em alguma medida explicada por questões étnicoraciais, seja pela repulsa baseada na questão de gênero, pois segundo Teixeira (2002), há "segregação de papéis, atitudes, poderes, enfim, lugares sociais desiguais para os diferentes sexos" e continua expondo que são "resultado de construções culturais reproduzidas e 
ressignificadas nas organizações escolares" (p.8), revelando que podem ocorrer mutações das ações desempenhadas pelos indivíduos, o que inclui o/no ambiente escolar, visto que existe um jogo de poder, também, nessa instituição.

Seja pela nossa herança escravocrata, seja pela nossa condição fenotípica, as formas e processos de classificação, hierarquização e estigmatização são elementos que teimam em justificar um sistema ideológico que se reinventa, mesmo agora, na contemporaneidade. $\mathrm{O}$ conceito de raça carrega consigo a ideia de poder e dominação, que sozinhas já seriam fortes instrumentos de inferiorização de sujeitos, mas juntas colaboram para essa divisão entre brancos e negros.

Um dos grandes desafios no enfrentamento à violência baseada em questões étnicoraciais e, mais especificamente, contra as juventudes negras, é que atores (escolas, organismos públicos e sociedade civil organizada) se vejam partícipes do processo de construção de ações preventivas, não sendo reduzida à esfera do Sistema de Defesa Social (Segurança Pública) a construção dessas soluções. O esforço para uma educação de qualidade, com maior reflexão sobre a vida em uma sociedade não é atividade individual, mas advém de um grande esforço coletivo.

Segundo a coordenadora de Ciências Humanas e Sociais da Unesco no Brasil, Marlova Noleto, apud PELLEGRINI (2014), "a violência nas escolas reproduz a violência na sociedade, não é um fenômeno intramuros isolado". A afirmativa reforça a ideia de que o ambiente escolar tem sido reprodutor de práticas violentas, dentre as quais o próprio racismo, que é uma forma de violência simbólica, mas que extrapola e se efetua na prática, haja vista o enfrentamento ao genocídio da juventude negra que se fundamenta nessa ideia de que o racismo também se manifesta fisicamente promovendo, inclusive, a morte de um número expressivo de jovens negros no Brasil.

Dentre muitos propulsores para o comportamento racista no contexto da educação, poderíamos citar a falta ou inversão de valores morais e éticos, desvalorização e desprezo institucional pela educação antirracista, banalização da violência e das práticas racistas; falta de valores morais e éticos, não seguindo às normas de convivência sociais; sentimento de impunidade por parte de quem reproduz o racismo; desestímulo profissional, carência de recursos e materiais adequados para a incorporação cotidiana dos pressupostos da Lei 10.639/03; currículos defasados, inadequados e restritivos; centralização excessiva das decisões nos órgãos superiores e Conselho Tutelar pouco atuante ou agindo contra as diretrizes de promoção da igualdade racial na educação (CORRÊA \& CARNEIRO, 2008).

A escola enquanto ente institucional acaba, muitas das vezes, por legitimar 
desigualdades raciais, que geram sistemas hierárquicos, machistas, elitistas e racistas. Entretanto, é nela onde se encontram, também, práticas e atores capazes de mudar o ideário equívoco, revelando as forças que movem os moinhos da igualdade e respeito. A escola tem esse papel que transcende o ato cognitivo:

\begin{abstract}
A ordem, o rigor, a limpeza, a propriedade, a fidelidade à palavra dada, a deferência à autoridade, o respeito ao outro, o cuidado tomado com as coisas, a paciência, a humildade, a capacidade de evitar à violência, o senso de cooperação ou de solidariedade, a capacidade de calar-se ou de assumir não caem do céu, mas de culturas familiares e de itinerários individuais muito diversos, de modo que alguns encontram na escola seu universo normativo familiar, enquanto outros ficam "sem rumo", privados de suas referências habituais (PERRENOUD, 2000, p.81).
\end{abstract}

Parece-nos que à escola é conferida certa responsabilidade que extrapola a sua competência, visto que muito do que é atribuído a ela constitui missão e tarefas dos pais, governos em todos os níveis, e da sociedade como um todo. O problema maior é quando a escola se estrutura a partir de vieses racistas. Parece um disparate afirmar tal ponto, mas recorrentemente discursos que legitimam tal percepção surgem de forma naturalizada, revelando que nossa sociedade ainda 'cultua' valores preconceituosos. Pensar a escola fora desse viés é mister, pois segundo Costa (1993, p.232): “de acordo com o imaginário social, a escola é um espaço sagrado, preservado, protegido, por isso mesmo incapaz de praticar qualquer forma de violência".

\footnotetext{
Uma educação permanente, realmente dirigida às necessidades das sociedades modernas, não pode continuar a definir-se em relação a um período particular da vida - educação de adultos, por oposição à dos jovens, por exemplo - ou a uma finalidade demasiado circunscrita - a formação profissional, distinta da formação geral. Doravante, temos de aprender durante toda a vida e uns saberes penetram enriquecem os outros (SOARES, 2002, p.41).
}

Segundo o autor, a formação é essencial para dar amplitude ao conhecimento por parte de alunos, o que é verdade, mas o que vemos é um pouco diferente. Seria muito imaturo pensarmos que as escolas não reproduzem práticas preconceituosas, visto que elas são geridas por indivíduos que podem, direta ou indiretamente, reproduzir práticas que estigmatizam e rotulam sujeitos. Ainda vivemos em um país onde a cor da pele, de uma ou outra forma, dita o futuro de cada um de nós.

\title{
3. Metodologia da pesquisa
}

Visando maximizar a captação da complexidade que a pesquisa em educação 
desencadeia e às suas múltiplas variáveis, utilizou-se o método quantitativo, atrelado a interpretação de dados em consonância com a base teórica, trazendo à tona implicações para com as subjetividades envolvidas.

\subsection{Universo da Pesquisa}

O ambiente escolar como espaço a ser analisado é primordial, pois vemos que a escola é capaz de promover práticas de liberdade e autonomia. Além disso, a análise do banco de dados de registros de ocorrências policiais, tendo Belo Horizonte como o local de enfoque é a espinha dorsal, já que através da análise desses dados foi possível identificar qual o perfil dos indivíduos mais vitimizados diante do fenômeno em debate.

O recorte feito para se pesquisar esse fenômeno, delimitando os estudantes do ensino médio, pauta-se no fato de serem indivíduos com maior idade o que, de certa forma, denotaria maior capacidade de reflexão, senso e maturidade para saber lidar com a diferença entre os sujeitos. Portanto, é interessante verificar se há relação entre maior maturidade e a prática de atos violentos no ambiente escolar. Estudar as instituições que tem sede em Belo Horizonte, Minas Gerais, visando à realização da pesquisa de campo, chama nossa atenção porque aguça conhecer a realidade que nós é próxima acerca de uma instituição tão popular e secular como é a escola pública.

A escolha do período entre 2014 e 2015 se justifica por contemplar anos anteriores e posteriores ao momento de realização do estudo, o que pode revelar repercussões, mudanças, permanências e alteridades.

A pesquisa documental será realizada através de bibliografia que dê suporte e sustentação por meio de revisão de literatura sobre o tema, por pilares teóricos escolhidos dentro da área de educação, psicologia e sociologia, coletados em livros, periódicos especializados, teses e dissertações que contenham informações e referências sobre o assunto. Tais elementos serão subsídios essenciais para se trabalhar os dados e informações disponibilizados pelas instituições objeto desse estudo, como por exemplo, as escolas e a Polícia Militar de Minas Gerais (PMMG).

\subsection{Procedimentos de coleta de dados}

$\mathrm{Na}$ pesquisa de campo os dados quantitativos foram fornecidos pela PMMG, por meio dos Registros de Eventos de Defesas Sociais (Reds), que são os registros popularmente conhecidos como Boletins de Ocorrências Policiais e vulgarmente chamados de B.O. São registros já tratados, ou seja, confirmados como sendo efetivamente de crimes, atos 

e-ISSN 2016/Atual: 2525-7870 | e-ISSN 2015/2016: 2447-018X

infracionais e contravenções cujos temas estão na esfera policial e que são, de fato, ocorridos no ou em função do ambiente escolar.

O Reds é o maior produto escrito e oficial que a o sistema de Defesa Social dispõe, sendo que a maioria de todos os registros são realizados pela $\mathrm{PMMG}$, pois é de sua competência a maior parte dos atendimentos. Sendo documento repleto de detalhes, ele alcança uma dimensão que permite ampliar observações e mesmo realidades sociais diversas, sendo material rico para inúmeras análises.

Os crimes/contravenções/atos infracionais escolhidos para essa investigação são àqueles constantes no Reds que versam sobre os crimes resultantes de preconceitos de raça ou de cor e coletados por meio do "Armazém de Dados SIDS_REDS_Ocorrências", que é alimentado pelos Registros de Eventos de Defesa Social (Reds), através de naturezas criminais especificas, sendo eles os constantes do quadro abaixo:

Figura 1- Naturezas Criminais de Preconceito Racial ou de Cor

\begin{tabular}{|l} 
CRIMES RESULTANTES DE PRECONCEITOS DE RACA OU DE COR (K07000) \\
IMPEDE ACESSO A CARGO DA ADM/SC UTIL/PUBL (K07003) \\
NEGAOBSTA EMPREGO EM EMPRESA PRIVADA (K07004) \\
IMPEDE ACESSO A COMERCIO/NAO SERVE CLIENTE (K07005) \\
IMPEDE INSCRICAO/INGRESSO EM ESTAB DE ENSINO (K07006) \\
IMPEDE ACESSO/HOSPEDAGEM EM HOTELISIMILAR (K07007) \\
IMPEDE ACESSO/SERVE EM RESTAURANTE/SIMILAR (K07008) \\
IMPEDE ACESSO/SERVE CASA DE DIVERSAO/SIMILAR (K07009) \\
IMPEDE ACESSO/SERVE CABELEIREIRO/SIMILAR (K07010) \\
IMPEDE ACESSO A ENTRADA DE EDIFICIO/SIMILAR (K07011) \\
IMPEDE ACESSO DE TRANSPORTE PUBLICO/SIMILAR (K07012) \\
IMPEDE ACESSO AO SERVICO MILITAR OBRIGATORIO (K07013) \\
IMPEDE CASAMENTO/CONVIVENCIA FAMILIAR/SOCIAL (K07014) \\
PRATICAINDUZINCITAIPRECONCEITO COR/DIVERSO (K07020) \\
USAFAZ/COMERCIALIZADIVULGA EMBLEMASIMILAR (K07201)
\end{tabular}

Fonte: Polícia Militar de Minas Gerais. Sids_Reds_Ocorrências. 2015.

Realizar esse estudo com base nos dados do Reds, é optar por uma fonte que, gerida pelos órgãos de Defesa Social, reflete uma realidade que desperta interesse quando avaliamos fenômenos sociais, que muitas das vezes, parecem recorrentes por serem, em tese, naturalizados. Trata-se de instrumento que permite recortes baseados na idade, sexo, cútis, gênero, por exemplo. Espera-se construir interpretação capaz de vislumbrar o fenômeno dada a complexidade do objeto de estudo, a partir de diferentes paradigmas.

\section{Breves resultados}

Os dados da pesquisa revelam que os agressores (autores) em sua maioria são do sexo masculino com destaque para indivíduos de cor parda, mas se somados negros e pardos 

e-ISSN 2016/Atual: 2525-7870 | e-ISSN 2015/2016: 2447-018X

representam mais de $75 \%$ da autoria de todos os delitos. Tal apontamento esbarra naquilo que é tido como especulação dentro do cenário da violência urbana, onde as pessoas acabam crendo que, uma população determinada parece ser o grande foco das atenções: a causadora, por assim dizer. Infere-se, conforme apontam os dados, que há certa tendência de que agentes pardos e negros do sexo masculino figurem com mais frequência como autores de eventos de Defesa Social em situações envolvendo ambientes escolares.

O número de vítimas envolvidas em registros policiais nos anos de 2014 e 2015, em Belo Horizonte, separados por cor de pele (cútis) e sexo (biológico), agrupados apresentam expressivos 26.390 (vinte e seis mil trezentos e noventa) indivíduos como vítimas de delitos em ambientes escolares. Sendo que desse total, (16.541) são do sexo feminino, sendo que tanto pessoas brancas quanto negras registram números próximos. Todavia, se somados negros e pardos representam pouco mais de $50 \%$ das vítimas. Considerando que todos os valores apontados aqui se referem às vítimas, havendo mudança apenas do sexo biológico e da cútis, em todas as três categorias, o número de vítimas do sexo feminino é bem superior ao do sexo masculino.

Logo, podemos observar que temos uma maioria de agressores composta por negros e pardos e uma maioria de vítimas formada também por esses grupos. Entretanto, é notório que há certa tendência de que as vítimas sejam pessoas do sexo feminino (condição biológica e não de gênero), mas não se pode afirmar o mesmo quanto a serem pessoas de cútis pardos e negros, pois há uma similaridade quando comparadas somente brancos (7.635) e pardos (7.541). Podemos inferir que o maior número de indivíduos envolvidos está na população de adolescentes, seguida da população de adultos e crianças. Se adicionarmos o quesito cútis, pessoas pardos aparecem em primeiro lugar, seguida da população de cútis branca e, em terceiro, a população de cútis negra, indiferente do sexo. A população de albinos e amarelos tiverem registros pouco expressivos quando comparados com as demais categorias em análise.

Se o processo normativo é uma forma de condicionar as pessoas em certos padrões, sem seguir princípios ético-políticos, ou seja, por imposição, gerando estigmatização e rótulos sociais específicos para com àquele que é diferente, logo, inferiorizando-os, é perceptível a urgência em adotarmos um sistema de educação que contemple a diversidade de forma que ultrapasse o "mundo das ideias" e se torne uma pratica real no ambiente escolar, buscando romper com barreiras arraigadas em velhos dogmas e valores.

\section{Conclusões}


Fruto de recorrente inquietação, esse estudo busca revelar a violência no ambiente escolar ou em função da escola, pois entende que ameaçados e amedrontados os cidadãos demandam por mais ações voltadas para superar prenoções e valores que negativam pessoas. Isso é fundamental para vencermos àquilo que nos foi dado como certo através de influências pelo olhar de outros que têm suas posições bem definidas em cada assunto, em cada momento.

Para melhor se entender a diferença, a concepção do outro, a vida e o sentido implicado no agir e ser do outro, é preciso dialogar e debater em ambientes que deveriam propiciar tais discussões, dentre eles, a escola. Local tido por muitos como sagrado, mas que vive envolta no profano (violência, depredação, preconceito, etc.). $\mathrm{O}$ que revela que as mazelas sociais alcançam também as instituições, mesmo às que são tidas como sagradas ou exemplos de gerar cidadãos (ou o que deveria ser).

Reside o impasse de que a sociedade não tem contemplado temáticas que abarcam outras visões de mundo e comportamentos na seara da diversidade. E é dada a escola a tarefa de resolver tamanha missão sozinha, como se outras instâncias e instituições e mesmo os pais e a sociedade como um todo não tivessem tal responsabilidade. Organismos de outras instâncias devem discutir e, quando for o caso, criar políticas públicas que tratem do tema em questão, rompendo com o passado conservador e se abrindo para as complexidades que o mundo nos impõe continuamente em meio a uma sociedade que agrega diversas gerações em um mesmo espaço.

\section{Referências}

ANISTIA INTERNACIONAL. Jovem negro vivo. Disponível em: https://anistia.org.br/campanhas/jovemnegrovivo/ Acesso em: 28 dez 2015.

BRASIL. Lei $\mathbf{n}^{\mathbf{0}}$ 12.288, de 20 de julho de 2010: Institui o Estatuto da Igualdade Racial, 2010.

CHARLOT, B. A violência na escola: como os sociólogos franceses abordam essa questão. Sociologias, Porto Alegre, n.8, p. 432-443, 2002.

CORRÊA, Silvia Saldanha; CARNEIRO, Maria Da Conceição Araújo. Violência no Meio Escolar: Desafio da Educação para a Cidadania. Montevideu, 2008.

COSTA, Eloísa Helena de Campos. A trama da violência na escola. Rio de Janeiro. 253p. Dissertação (mestrado). Fundação Getúlio Vargas, 1993. 

e-ISSN 2016/Atual: 2525-7870 | e-ISSN 2015/2016: 2447-018X

DAYRELL, Juarez. A escola "faz" juventudes? Reflexões em torno da socialização juvenil. In: Educação e sociedade. Campinas, vol.28, n.100- Especial, p. 1.105-1.128, out. 2007.

EXAME, Revista. Liceu de Aristóteles: novo parque arqueológico em Atenas. 2014. Disponível em: <http://exame.abril.com.br/estilo-de-vida/noticias/liceu-de-aristoteles-novoparque-arqueologico-em-atenas. Acesso em: 22 jan 2016.

GOMES, Nilma Lino. Corpo e Cabelo como ícones de construção de beleza e da identidade negra nos salões étnicos de Belo Horizonte. Tese de Doutorado. Faculdade de Filosofia, Letras e Ciências Humanas, USP. 2002.

Educação e relações raciais: Refletindo sobre algumas estratégias de atuação. In: Revista USP, São Paulo, nº 68, p.46-57, dezembro/fevereiro 2005.

Alguns termos e conceitos presentes no debate sobre relações raciais no Brasil: uma breve discussão. 2012. Disponível em: $<$ http://www.acaoeducativa.org.br/fdh/wp-content/uploads/2012/10/Alguns-termos-econceitos-presentes-no-debate-sobre-Rela\%C3\%A7\%C3\%B5es-Raciais-no-Brasil-umabreve-discuss\%C3\%A3o.pdf. > Acesso 23 abr 2016.

GUIMARÃES, Antônio Sérgio Alfredo. Raça, cor, cor de pele e etnia. Revista Cadernos de campo. São Paulo, v.20, p. 1-360, Jan-Dez./2011. Revistas dos alunos de pós-graduação em Antropologia Social da USP.

MUNANGA, Kabengele. Identidade, cidadania e democracia: algumas reflexões sobre os discursos antirracistas no Brasil. In: SPINK, Mary Jane Paris (Org.) A cidadania em construção: uma reflexão transdisciplinar. São Paulo: Cortez, p. 177-187, 1994.

NOLETO, Marlova. In: PELLEGRINI, Luiz. Violência nas escolas: ela reproduz as loucuras da nossa 2014.2 Disponível em: http://www.brasil247.com/pt/247/revista_oasis/140608/Viol\%C3\%AAncia-nas-escolas-elareproduz-as-loucuras-da-nossa-sociedade.htm. Acesso em 10 out 2016.

PERRENOUD, Philippe. Pedagogia diferenciada: das intenções à ação. Porto Alegre: Artes Médicas Sul, 2000.

SANTOS, Sales Augusto dos. Ação Afirmativa ou a Utopia Possível: o perfil dos professores e dos pós-graduandos e a opinião destes sobre ações afirmativas para os negros ingressarem nos cursos de graduação da UnB. Relatório Final de Pesquisa. Brasília: ANPEd/ $2^{\circ}$ Concurso Negro e Educação, mimeo, 2002.

SOARES, Leôncio. Diretrizes Curriculares Nacionais. Educação de jovens e adultos. Rios de Janeiro, DP\&A, 2002. 